(c) American Dairy Science Association, 2006.

\title{
Effect of Hoof Pathologies on Subjective Assessments of Dairy Cow Gait
}

\author{
F. C. Flower ${ }^{1}$ and D. M. Weary \\ Animal Welfare Program, Faculty of Food and Land Systems, The University of British Columbia, \\ Vancouver, Canada
}

\begin{abstract}
To explore how hoof pathologies affect dairy cattle gait, we studied cows with sole hemorrhages $(n=14)$, sole ulcers $(n=7)$, and those with no visible injuries $(\mathrm{n}=17)$. Overall gait assessments, scored from video using a 1 to 5 numerical rating system ( $1=$ sound, $5=$ severely lame) and a continuous 100-unit visual analog scale, found cows having sole ulcers had poorer gait than healthy cows (mean \pm SEM: $4.0 \pm 0.13$ vs. $3.1 \pm$ 0.08 , and $59 \pm 3$ vs. $46 \pm 2$, respectively). Six gait attributes (back arch, head bob, tracking-up, joint flexion, asymmetric gait, and reluctance to bear weight) were also assessed using continuous 100-unit scales. Compared with healthy cows, those having sole ulcers walked with a more pronounced back arch (12 \pm 3 vs. $28 \pm 4$ ), more jerky head movement ( $2 \pm 2$ vs. $10 \pm 3$ ), shortened strides ( \pm 2 vs. $26 \pm 4$ ), and more uneven weighting among the limbs (16 \pm 2 vs. $32 \pm 3$ ). Of all measures, the numerical rating system most effectively discriminated healthy cows from those with sole ulcers $\left(\mathrm{R}^{2}=0.73\right)$, classifying $92 \%$ of animals correctly. No differences were detected among cows with and without sole hemorrhages. Intra- and interobserver reliabilities were reasonable for all measures $\left(R^{2} \geq 0.64\right)$ except joint flexion and asymmetric gait. In summary, subjective assessments of dairy cattle gait provide valid and reliable approaches to identifying cattle with sole ulcers.
\end{abstract}

Key words: cattle, lameness, behavior, hoof pathology

\section{INTRODUCTION}

Lameness is recognized as a source of economic loss for producers, and of pain and discomfort for cows (Russell et al., 1982; Warnick et al., 2001; Green et al., 2002). Current literature indicates that producers find it difficult to identify cows at early stages of lameness, because cattle tend to show little overt behavioral response until injuries are advanced (O'Callaghan, 2002). Whay et al.

Received June 9, 2005.

Accepted August 23, 2005.

${ }^{1}$ Corresponding author: fcf@interchange.ubc.ca
(2003) reported that producers were able to detect only $25 \%$ of lame cows, and Mill and Ward (1994) found that 13 of 15 producers could only identify lame cows that showed an obvious limp. Rather than identifying cows at these more severe stages of lameness, when costs of treatment are high and recovery is slow, methods are required to identify them at the early stages of lameness.

The most commonly used approach to detect lame cows is to assess some aspect of their walking gait. Several different systems exist, often termed lameness or locomotion scoring systems, such as those developed by Manson and Leaver (1988) and Sprecher et al. (1997). These scoring systems rank the gait of animals, typically on a 1 to 5 scale, for the presence or absence of certain behaviors and postures thought to be indicative of lameness (Manson and Leaver, 1988; Kestin et al., 1992; Welsh et al., 1993; Sprecher et al., 1997).

Usefulness of any assessment method is limited by its validity, reliability, and sensitivity. Little is known, however, about how gait-scoring systems for cattle perform in relation to these criteria. One way to evaluate the validity of an assessment method is to simply compare scores in cows with and without known pathologies. Those studies that have attempted to examine the validity of gait scoring systems report poor relationships between scores and measures of hoof and leg injuries or disease. For example, in one study, the presence of sole lesions accounted for only $22 \%$ of the variation in gait scores (van Eerdenburg et al., 2003), and in another, the presence of known injuries accounted for $48 \%$ of the variance in gait scores (Whay et al., 1997).

As with any subjective technique, scoring systems can vary in reliability. Even the same observer may not score the gait of a cow the same on 2 occasions. For example, O'Callaghan et al. (2003) reported that a trained observer rescoring the gait of 129 cows was consistent for only $56 \%$ of observations. In addition, a lack of agreement between observers also has been reported; O'Callaghan et al. (2003) found only 37\% agreement in the scores of 2 observers, and Winckler and Willen (2001) found 68\% agreement among scores of 3 observers. Use of more specific terms and detailed 
descriptions to categorize animals may help reduce such variability in observer scores.

The Manson and Leaver (1988) and Sprecher et al. (1997) systems assign discrete scores to animals. Another approach is to assess lameness on a continuous scale. For example, Welsh et al. (1993) found that a continuous scale for assessing lameness in sheep was more sensitive than a standard numerical rating system. Although more variation exists among continuous than discrete variables (e.g., Engel et al., 2003), using a continuous scale is probably more sensitive, allowing observers to record more subtle changes in behavior. Both the continuous scale and the numerical rating system, however, are based on a simultaneous evaluation of multiple gait attributes. A new approach to lameness assessment used in the current study was to divide gait into specific gait attributes, scoring each attribute separately on a continuous scale, providing a more detailed profile of each cow's gait.

In the current study, we compared gait measures of lactating dairy cows with and without visible hoof pathologies, with the aim of evaluating 4 aspects of subjective gait assessments: 1) validity of the methods (i.e., do they relate to hoof pathologies), 2) reliability of assessments (i.e., how well correlated are observations within and among observers), 3) whether continuous measures are better than numerical rating systems at predicting hoof pathologies, and 4) whether specific gait attributes can be used alone or in combination to predict hoof pathologies.

\section{MATERIALS AND METHODS}

\section{Cows and Management}

We studied 48 high-producing loose-housed Holstein dairy cows at the University of British Columbia's Dairy Education and Research Centre (Agassiz, Canada). Individual cows were selected randomly from the highproducing herd, with the constraint that 24 were primiparous and 24 were multiparous. Following hoof health assessment (see below), 8 cows with digital dermatitis were excluded and 2 were dropped for management reasons. The remaining primiparous $(\mathrm{n}=18)$ and multiparous cows (parity $=2$ to $7 ; \mathrm{n}=20$ ) differed in BCS (3.1 \pm 0.3 vs. $2.9 \pm 0.3 ; P<0.05)$ and daily milk production $(28.7 \pm 4.3$ vs. $48.9 \pm 6.3 \mathrm{~kg} ; P<0.001)$, but not DIM (96 \pm 39 vs. $74 \pm 37 \mathrm{~d}$; NS).

Cows were milked twice daily in a parlor at 0500 and $1600 \mathrm{~h}$, fed twice daily a TMR formulated to meet or exceed NRC (2001) requirements, and had free access to water in self-filling troughs. Stalls were deep-bedded with sand $(0.40 \mathrm{~m})$ and the flooring within $1.85 \mathrm{~m}$ of the feed bunk was grooved, $2.5 \mathrm{~cm}$-thick rubber. Elsewhere in the pen, flooring was grooved concrete. Cows were cared for according to the standards of the Canadian Council on Animal Care and a protocol approved by the University of British Columbia's Animal Care Committee.

\section{Data Collection}

Video Recordings. To habituate cows to the filming conditions, cattle were walked to and from the milking parlor every day for $4 \mathrm{wk}$, along a 40-m grooved concrete test alley. A rope barrier in the test alley forced cows to walk in a straight line in single file with minimal side-to-side movement. The cows were allocated to 2 groups for management purposes. The first group of 24 cows was filmed after morning milking (between 0540 and $0810 \mathrm{~h}$ ) for 7 consecutive days and then the procedure was repeated on the second group of 24 cows during the next $7 \mathrm{~d}$. The test alley was cleaned with automatic scrapers at the beginning of each recording session.

A video camera (Panasonic AG-195MP, Matsushita Electric, Mississauga, Ontario) was fixed in position $6.75 \mathrm{~m}$ perpendicular to the line of progression of each cow. The camera captured cows walking the midsection of the test alley (length $7.05 \mathrm{~m}$, width $1.15 \mathrm{~m}$ ) and recorded cows from the left side on return from the milking parlor. At least 2 consecutive strides were recorded per cow at every recording session.

Subjective Assessment of Gait. A trained observer (observer 1) scored video recordings using: 1) a numerical rating system (NRS) with detailed descriptions, 2) an overall visual analog scale (VAS), and 3) an evaluation of 6 specific gait attributes using a VAS. The NRS was based on a 5-point scale, in which a score of 1 represented a sound animal and 5 represented a severely lame animal (Table 1 ). If a cow exceeded the requirements of a particular score, but did not meet all the requirements of the next successive score, a halfinteger score was allocated. A continuous 100-unit VAS was used to assess overall lameness (overall VAS) and 6 specific gait attributes associated with lameness (Table 2). Both ends of the scale had a description of the extreme forms of the condition. For example, degree of back arch had "flat" at one end (0) of the scale and "convex" at the other end (100), where "convex" represented the most extreme back arch the observer had seen in their experience. The observer recorded directly on a computer screen a position on the scale that represented the severity of the behavior observed. Each video recording was observed 14 times: twice for each of the 6 gait attributes (in the order listed in Table 2), once for the overall VAS, and then once for the NRS. Of 336 video recordings, 25 were not scored because cows stopped, stumbled, slipped, defecated, urinated, or per- 
Table 1. Numerical rating system for walking dairy cows

\begin{tabular}{|c|c|c|}
\hline Score & Description & Behavioral criteria \\
\hline 1.0 & Smooth and fluid movement & $\begin{array}{l}\text { Flat back } \\
\text { Steady head carriage } \\
\text { Hind hooves land on or in front of fore-hooves (track-up) } \\
\text { Joints flex freely } \\
\text { Symmetrical gait } \\
\text { All legs bear weight equally }\end{array}$ \\
\hline 2.0 & $\begin{array}{l}\text { Imperfect locomotion but ability to } \\
\text { move freely not diminished }\end{array}$ & $\begin{array}{l}\text { Flat or mildly arched back } \\
\text { Steady head carriage } \\
\text { Hind hooves do not track up perfectly } \\
\text { Joints slightly stiff } \\
\text { Slightly asymmetric gait } \\
\text { All legs bear weight equally }\end{array}$ \\
\hline 3.0 & $\begin{array}{l}\text { Capable of locomotion but ability } \\
\text { to move freely is compromised }\end{array}$ & $\begin{array}{l}\text { Arched back } \\
\text { Steady head carriage } \\
\text { Hind hooves do not track-up } \\
\text { Joints show signs of stiffness } \\
\text { Asymmetric gait } \\
\text { Slight limp can be discerned }\end{array}$ \\
\hline 5.0 & $\begin{array}{l}\text { Ability to move is severely restricted } \\
\text { and must be vigorously encouraged to move }\end{array}$ & $\begin{array}{l}\text { Extremely arched back } \\
\text { Obvious head bob } \\
\text { Poor tracking-up with short strides } \\
\text { Obvious joint stiffness characterized by lack of joint flexion } \\
\text { with very hesitant and deliberate strides } \\
\text { Asymmetric gait } \\
\text { Inability to bear weight on one or more limbs }\end{array}$ \\
\hline
\end{tabular}

formed a gait other than walking. One recording was not scored because a cow walked too closely to another, potentially affecting the gait of both cows. To estimate intraobserver reliability, observer 1 rescored recordings from $1 \mathrm{~d}$ selected at random, at least $7 \mathrm{~d}$ after the first scoring session, for each cow. To estimate interobserver reliability, a second trained observer (observer 2) scored and rescored this same sample of recordings. Both ob- servers had at least $1 \mathrm{yr}$ of experience in scoring gait using these techniques.

Clinical Assessment of Hooves. Injuries to the corium, the highly vascularized tissue responsible for producing hoof horn tissue, are not immediately visible on the surface of the sole. Damage to the corium results in hemorrhages, and in more severe cases, poor quality or no horn production (Ossent et al., 1997). Under nor-

Table 2. Description of 6 gait attributes associated with lameness ${ }^{1}$

\begin{tabular}{|c|c|c|}
\hline Gait attribute & \multicolumn{2}{|c|}{ Endpoints of visual analog scale } \\
\hline Back arch & Flat spine & Convex arch between the withers and tailbone \\
\hline Tracking-up & Hind hoof falls in imprint left by the front hoof & $\begin{array}{l}\text { Hind hoof falls short of imprint left by } \\
\text { the front hoof }\end{array}$ \\
\hline Joint flexion & $\begin{array}{l}\text { Flexes and extends limbs through the } \\
\text { normal range of motion }\end{array}$ & $\begin{array}{l}\text { Limited flexion and extension resulting } \\
\text { in stiffness }\end{array}$ \\
\hline
\end{tabular}

${ }^{1}$ Scored on a 100 -unit continuous visual analog scale. A score of 0 represents a sound gait attribute and 100 represents the most extreme example possible. 
mal conditions of hoof growth and wear, hemorrhages become visible approximately 8 to $10 \mathrm{wk}$ after the occurrence of corium damage (Bergsten and Frank, 1996; Lischer and Ossent, 2000), but there is no reason to believe that the corium is still injured or painful at this stage. In cases in which corium damage is sufficiently severe that the sole becomes ulcerated, the injury may well continue to be painful even when fully visible at the surface of the sole. As we wished to understand how gait was affected by painful injuries, we recorded the presence of sole hemorrhages (SH) and sole ulcers (SU) after a professional hoof trimmer trimmed the front and hind hooves of each cow 8 to 9 wk after the gait assessment.

An experienced observer examined each hoof and recorded the presence of lesions using a modified version of a lesion scoring system (Greenough and Vermunt, 1991). Number, location, and severity of lesions on each hoof were scored on a 4-point scale [1 = slight discoloration, $2=$ moderate hemorrhagic lesion, $3=$ severe hemorrhagic lesion, $4=$ sole ulcer (exposed corium)]. We also noted at this time the presence and location of digital dermatitis, both active (ulcerative or exudative lesions at the heel, with or without hair-like projections, painful to touch) and healed forms (dry, brown scabrous tissue, unresponsive to touch), as well as other foot pathologies such as interdigital hyperplasia and interdigital necrobacillosis.

Hoof health data of 2 cows were not collected because the cows were dropped from the trial due to coliform mastitis and early dry off for management reasons. Of the 46 cows examined, the majority had hoof pathologies $(63 \%)$ at the time of examination. No cases of interdigital hyperplasia, interdigital necrobacillosis, or healed digital dermatitis were recorded; however, presence of active digital dermatitis was noted on 8 cows. Because we could not be certain whether digital dermatitis was present at the time of video recording, these cows were dropped from the analysis. The remaining 38 cows were grouped into 3 mutually exclusive hoof health categories: 1 ) healthy cows with no visible signs of injury or disease on hooves ( $\mathrm{n}=17)$; 2 ) cows having only $\mathrm{SH}(\mathrm{n}=14)$; and 3$) \mathrm{SU}$ cows having exposed corium and $\mathrm{SH}(\mathrm{n}=7)$.

\section{Statistical Analyses}

Measures from each of the 7-d recordings were averaged to provide 1 value per cow. To test the effect of hoof health ( $2 \mathrm{df}$ ) on all dependent variables, we used contrast statements within the GLM procedure of SAS (SAS Inst. Inc., Cary, NC) to test for our specific predictions that: 1 ) cows with $\mathrm{SH}(1 \mathrm{df})$ walked differently than healthy animals and 2 ) cows with SU (1 df) walked differently than healthy cows. Residuals were examined to verify normality and homogeneity of variances. The 6 behavioral gait attributes also were used in the Stepwise Discriminant Analysis procedure of SAS to determine which combination of specific gait measures could most accurately assign cows to 1 of the 3 hoofhealth groups. The criterion for entering or leaving the model was an alpha value of 0.15 . Coefficients of determination $\left(R^{2}\right)$ were calculated using the regression procedure (PROC REG) of SAS between 1) first and second observations to test intraobserver reliability for observers 1 and 2, and 2) between the mean values for the 2 observers to test interobserver reliability.

\section{RESULTS}

\section{Validity}

The walking gait profile of cows having SU differed from that of healthy animals (Table 3). Both the NRS and overall VAS assessments of lameness illustrated that cows having these pathologies had higher assessment scores than healthy animals. When walking behavior was broken down into specific gait attributes, SU cows typically had more pronounced back arch, more jerky head movement, shorter strides, stiffer joint movements, more uneven hoof placement, and appeared more reluctant to bear weight evenly on all 4 limbs. The gait profiles of SH cows did not differ from those of healthy cows.

As older cows are more susceptible to injuries, we reanalyzed the data considering only multiparous cows. As with the analysis considering all cows, multiparous cows having SU $(\mathrm{n}=6)$ differed $(P<0.05)$ from healthy cows $(n=5)$ in overall NRS and VAS as well as back arch, tracking-up, joint flexion, asymmetric gait, and reluctance to bear weight.

Given that cows with SU were different from healthy animals, stepwise discriminant analysis compared these 2 groups only. Overall VAS was effective in separating the 2 groups $\left(R^{2}=0.52, P<0.001\right.$; Figure $\left.1 a\right)$. Of all the measures recorded, however, the most effective at separating healthy cows from those having SU was NRS $\left(R^{2}=0.73, P<0.001\right.$; Figure $\left.1 b\right)$. Accuracy of classifying cows into healthy or SU groups by NRS and overall VAS were very high at $92 \%$ (22 of 24 observations correctly classified by the model). Of the 6 gait attributes, the final stepwise model included only reluctance to bear weight. This model accounted for 51\% of the variance in hoof health $(P<0.001$; Figure $1 \mathrm{c})$, but was also able to correctly classify 22 of 24 cases.

\section{Reliability}

High intraobserver reliability was found for the NRS, overall VAS, head bob, and tracking-up variables (Table 
Table 3. Least squares means $( \pm$ SEM) of gait-scoring variables for healthy cows $(n=17)$, those having sole hemorrhages $(\mathrm{n}=14)$, and those with sole ulcers $(\mathrm{n}=7)$

\begin{tabular}{llcc}
\hline & \multicolumn{3}{c}{ Hoof condition } \\
\cline { 2 - 4 } Variable & Healthy & Sole hemorrhage & Sole ulcer \\
\hline Numerical rating system $^{1}$ & $3.1 \pm 0.08$ & $3.3 \pm 0.09$ & $4.0 \pm 0.13^{* * * *}$ \\
Overall visual analog scale $^{2}$ & $46 \pm 2$ & $48 \pm 2$ & $59 \pm 3^{* * *}$ \\
Back arch $^{2}$ & $12 \pm 3$ & $19 \pm 3$ & $28 \pm 4^{* *}$ \\
Head bob $^{2}$ & $2 \pm 2$ & $5 \pm 2$ & $10 \pm 3^{*}$ \\
Tracking up $^{2}$ & $7 \pm 2$ & $12 \pm 3$ & $26 \pm 4^{* * *}$ \\
Joint flexion $^{2}$ & $21 \pm 2$ & $23 \pm 2$ & $32 \pm 2^{* * *}$ \\
Asymmetric gait $^{2}$ & $18 \pm 2$ & $22 \pm 2$ & $27 \pm 3^{* *}$ \\
Reluctance to bear weight $^{2}$ & $16 \pm 2$ & $19 \pm 2$ & $32 \pm 3^{* * *}$ \\
\hline
\end{tabular}

${ }^{1}$ Numerical rating system scored on a 5 -point scale (see Table 1 ).

${ }^{2}$ Variables were scored on continuous 100-unit visual analog scales (see Table 2).

*Different $(P<0.05)$ from healthy cows.

**Different $(P<0.01)$ from healthy cows.

***Different $(P<0.001)$ from healthy cows.

4). Observer 1 also showed consistent scores for back arch, especially for more pronounced cases (Figure 2). Other variables, such as joint flexion and asymmetric gait, were scored less consistently by the same observer. Interobserver reliability tended to be lower than intraobserver estimates, but the 2 observers were reasonably consistent in their estimates of some variables such as the overall VAS.

\section{DISCUSSION}

Few studies have assessed the validity of subjective gait assessments to identify lame dairy cattle, and those that have report only weak relationships between hoof pathologies and gait scores. For example, Whay et al. (1997) reported that only $48 \%$ of variance in lesion severity was explained by an NRS. In the current study, we found that the NRS and overall VAS scores successfully distinguished cows having SU from healthy cows (with 22 of 24 cows correctly classified). The amount of variation explained by the NRS used in this study (73\%) was much greater than reported in previous work, perhaps because the NRS used in the current study included detailed descriptions of each score. The NRS also provided a better estimate of hoof pathologies than the overall VAS, probably because the NRS used defined points. Other variation, not explained by the NRS, could result from other injuries not recorded. For example, we were unable to diagnose lameness caused by internal injuries or disease in the upper limb, because we did not have the tools available to identify such conditions.

One of the unique contributions of this study is that we divided gait into separate attributes and found that scores for back arch, tracking-up, and reluctance to bear weight differentiated between SU and healthy cows. These results indicate that assessing specific gait attri- butes can be worthwhile. However, stepwise discriminant analysis was not able to form a combination of these variables that was any more successful at assigning cows to hoof health groups than the NRS. The SU cows had shorter strides and greater reluctance to bear weight when assessed subjectively. More objective methods of assessing these gait attributes might provide better discrimination between cows with and without hoof pathologies. For example, Flower et al. (2005) used kinematic measurements on the same sample of cows as described in the current study, and found that these objective measures were also able to discriminate between healthy cows and those with SU. In addition, Rajkondawar et al. (2002) successfully used measures of limb loading from force plates to identify lame dairy cows. Unfortunately, the technology required for these objective assessments is not readily accessible for many farms, meaning that subjective methods are still required for on-farm evaluations.

No significant differences were found in the gait of healthy cows and those having SH. The corium injuries leading to these hemorrhages may not be painful enough to alter gait, or grouping animals with minor, moderate, and severe hemorrhages may have masked differences among groups. Indeed, Whay et al. (1997) suggested that mild lesions are probably not sufficiently painful to affect gait. Future studies should investigate the influence of hemorrhage severity on gait using a larger and more variable sample of cows with hemorrhages than was available in the current study.

We found reasonable levels of intraobserver reliability for NRS, overall VAS, head bob, tracking-up, and back arch. Manson (1986) reported similar intraobserver reliability for her overall gait score of dairy cattle $\left(R^{2}=0.79\right)$, although these cows were observed from behind and scored live. Some specific gait attri- 

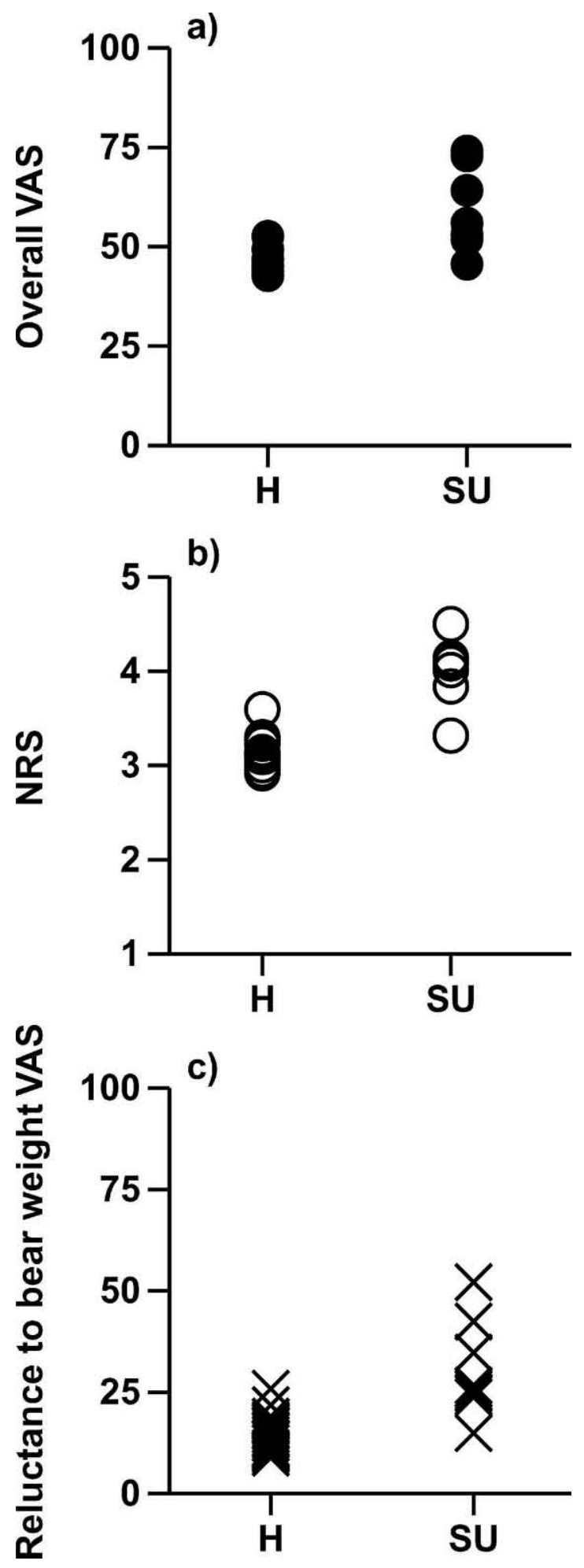

Figure 1. Plot of a) overall visual analog scale (VAS, ๑) measured using a 100-unit VAS, b) 5-pt numerical rating system (NRS, $\bigcirc$ ), and c) reluctance to bear weight $(\times)$ measured using a 100-unit VAS. Each plot shows healthy cows $(\mathrm{H} ; \mathrm{n}=17)$ and those with sole ulcers (SU; $\mathrm{n}=7$ ). butes, like joint flexion and asymmetric gait, were scored less consistently in the current study, suggesting that these variables are more difficult to score. Consistency may be improved by using clearer definitions. For example, Garner et al. (2002) found that consistency improved when more detailed descriptions of broiler gait categories were provided. If consistency does not improve with better descriptions, however, we should consider dropping these behaviors from future studies. Intraobserver reliability obviously limits interobserver reliability because different observers can be no more consistent than single observers are with themselves. Our estimate of interobserver reliability, however, was still reasonable for some variables such as NRS, and our estimate for this variable $\left(R^{2}=0.69\right)$ agreed well with that of Manson $\left(1986 ; R^{2}=0.71\right)$.

Observers may vary in their assessments in part because cows vary in the way they walk. In this study, we controlled for some of this variation by scoring the same video recording. Previous studies that report reliability of gait scores usually present only the percentage agreement and not where the greatest variation of scores occurred (e.g., O'Callaghan et al., 2003). Our results suggest that intraobserver reliability for back arch (and other variables not illustrated) is greatest at the higher end of the scale, suggesting that cows with mild gait defects are more difficult to evaluate. Winckler and Willen (2001) reported similar results for interobserver reliability, with most disagreement among observers at the lower end of the gait-scoring scale.

Typically, a delay of 8 to $10 \mathrm{wk}$ exists between the time corium damage occurs and the time a hemorrhage or ulcer becomes visible on the sole of the hoof (Bradley et al., 1989; Bergsten and Frank, 1996; Lischer and Ossent, 2000). Based on these findings, hoof examinations in the current study occurred 8 to 9 wk after the end of the trial providing information on the presence of SH and SU. If we had scored hooves on the day of gait assessment, only hemorrhages that had formed 8 to $10 \mathrm{wk}$ earlier (i.e., well before the gait assessment) would have been visible. Our choice of when to record lesions was based on the best evidence available regarding the time between injury to the corium and when signs of a lesion (i.e., hemorrhages and ulcers) become visible at the surface of the sole. Our aim was to assess the effects of these injuries to the corium on gait. A potential source of variation in our study, however, was the time course of more acute pathologies such as digital dermatitis. Future studies concerned with these factors may choose to use different hoof sampling frequencies.

Location of hoof pathologies may affect which behavioral gait attributes are exhibited when cows walk. For example, back arch may only occur with pathologies located on the rear hooves. Unfortunately, in this study, 
Table 4. Coefficients of determination $\left(R^{2}\right)$ for intra- and interobserver reliability of gait-scoring variables $(\mathrm{n}=46)$

\begin{tabular}{llll}
\hline & \multicolumn{2}{c}{ Intraobserver reliability } & \\
\cline { 2 - 3 } Variable & Observer 1 & Observer 2 & $\begin{array}{l}\text { Interobserver } \\
\text { reliability }\end{array}$ \\
\hline Numerical rating system & 0.76 & 0.85 & 0.69 \\
Overall visual analog scale & 0.82 & 0.76 & 0.73 \\
Back arch & 0.84 & 0.82 & 0.69 \\
Head bob & 0.82 & 0.77 & 0.73 \\
Tracking up & 0.90 & 0.86 & 0.83 \\
Joint flexion & 0.57 & 0.56 & 0.38 \\
Asymmetric gait & 0.35 & 0.50 & 0.48 \\
Reluctance to bear weight & 0.64 & 0.72 & 0.69 \\
\hline
\end{tabular}

SU were only found on the hind hooves. Although we could not test for location of injury (e.g., front vs. hind), future work should investigate how location of pathology affects cow gait.

Average gait scores were high in this study, even among apparently healthy cows. Little literature is available on average gait scores for healthy cows, and almost no results are available for high-producing cows in loose-housed systems with concrete flooring. The elevated gait scores observed in the current study, however, should not seem too surprising given how many cows have significant hoof pathologies. For example, Manske et al. (2002) found that $72 \%$ of cows investigated in Swedish herds had at least 1 hoof lesion. Similarly, Somers et al. (2003) surveyed herds in The Netherlands and found that $80 \%$ of the cows exposed to

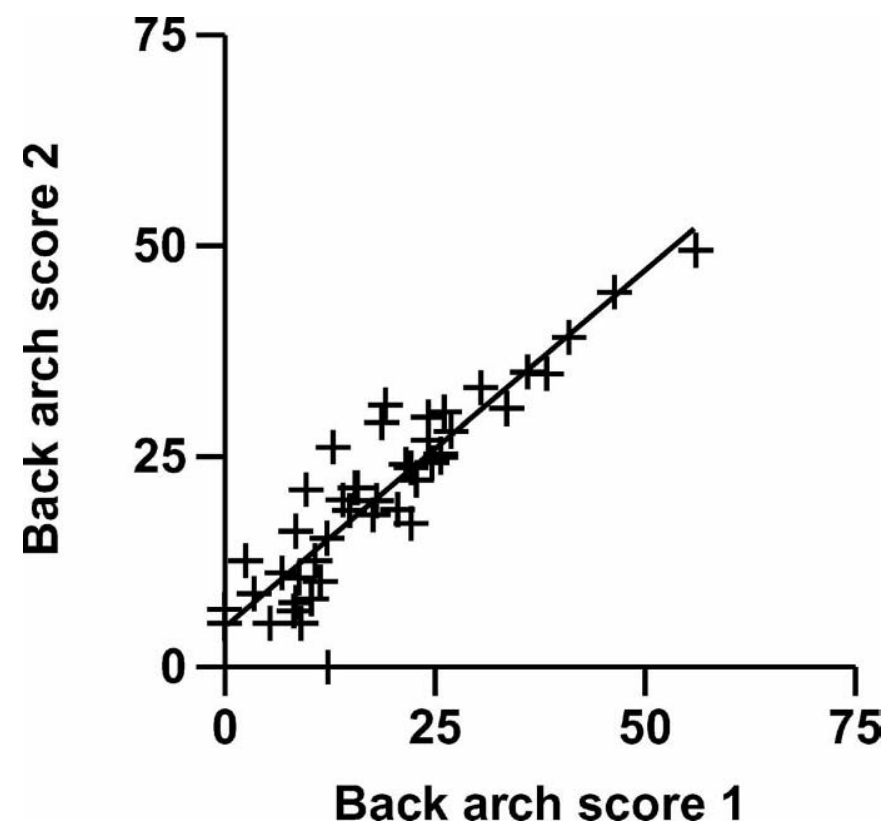

Figure 2. Intraobserver repeatability of observer 1 for back arch $\left(\mathrm{R}^{2}=0.84 ; \mathrm{n}=46\right)$. concrete flooring had at least 1 claw disorder at the time of observation. We suspect that the values reported in our study are not beyond the expected range for midlactation Holsteins housed in free-stall barns.

The elevated gait scores may also be explained by the surface upon which cows walked. Previous work has shown that gait patterns change in response to the coefficient of friction of the flooring surface (Phillips and Morris, 2001; Telezhenko and Bergsten, 2005). Telezhenko and Bergsten (2005) also reported that cows walking on solid concrete floors had worse gait than on more yielding surfaces, such as rubber. For example, shorter stride lengths were observed on solid concrete vs. rubber (1.48 \pm 0.02 vs. $1.54 \pm 0.02 \mathrm{~m}$, respectively). Even though the alley was scraped before each recording in the current study, cows may have found the hard concrete surface slippery, or anticipated that it would be, resulting in higher scores.

In summary, the results from this study suggest that certain methods of gait assessment, such as the numerical rating system and overall visual analog scales used, are both valid and reliable for identifying cows with SU. Other variables, such as joint flexion and asymmetric gait, showed limited reliability and are likely of little value when scored separately. Numerical rating systems were better at predicting SU than any other measures, and although most gait attributes were also able to predict such injuries, a combination of these variables was no more successful at identifying SU than the numerical rating system. New research is now required to: 1) determine which gait attributes are necessary in composite scoring systems, 2) evaluate how subjective assessments compare with more objective methods of assessing gait in dairy cattle, and 3) identify effects of other hoof and foot pathologies on gait.

\section{ACKNOWLEDGMENTS}

We thank the faculty, staff, and students at University of British Columbia's Dairy Education and Research Centre and the University's Animal Welfare Pro- 
gram, especially Anne Marie de Passillé, Nelson Dinn, José Fregonesi, David Fraser, Jeff Rushen, David Sanderson, the late Jim Shelford, and Christoph Winckler for their help during the study. We would also like to thank Amanda Zimmerman for developing the gaitscoring system, Gosia Zdanowicz for gait scoring cows for the interobserver analysis, and Erin Bell for conducting hoof health examinations. The project was funded by the Natural Sciences and Engineering Research Council of Canada through the Industrial Research Chair in Animal Welfare, and by contributions from the British Columbia SPCA, the British Columbia Veterinary Medical Association, the Dairy Farmers of Canada, the British Columbia Dairy Foundation and many others listed at http://www.landfood.ubc.ca/animalwelfare/.

\section{REFERENCES}

Bergsten, C., and B. Frank. 1996. Sole haemorrhages in tied primiparous cows as an indicator of periparturient laminitis: Effects of diet, flooring and season. Acta Vet. Scand. 37:383-394.

Bradley, H. K., D. Shannon, and D. R. Neilson. 1989. Subclinical laminitis in dairy heifers. Vet. Rec. 125:177-179.

Engel, B., G. Bruin, G. Andre, and W. Buist. 2003. Assessment of observer performance in a subjective scoring system: Visual classification of the gait of cows. J. Agric. Sci. 140:317-333.

Flower, F. C., D. J. Sanderson, and D. M. Weary. 2005. Effects of hoof pathologies on kinematic measures of dairy cow gait. J. Dairy Sci. 88:3166-3173.

Garner, J., C. Falcone, P. Wakenell, M. Martin, and J. Mench. 2002. Reliability and validity of a modified gait scoring system and its use in assessing tibial dyschondroplasia in broilers. Br. Poult. Sci. 433:355-363.

Green, L. E., V. J. Hedges, Y. H. Schukken, R. W. Blowey, and A. J. Packington. 2002. The impact of clinical lameness on the milk yield of dairy cows. J. Dairy Sci. 85:2250-2256.

Greenough, P. R., and J. J. Vermunt. 1991. Evaluation of subclinical laminitis in a dairy herd and observations on associated nutritional and management factors. Vet. Rec. 128:11-17.

Kestin, S. C., T. G. Knowles, A. E. Tinch, and N. G. Gregory. 1992. Prevalence of leg weakness in broiler chickens and its relationship with genotype. Vet. Rec. 131:190-194.

Lischer, C. J., and P. Ossent. 2000. Sole ulcers in dairy cattle-what's new about an old disease? Pages 46-48 in Proc. XI Int. Symp. Disorders of the Ruminant Digit, Parma, Italy.

Manske, T., J. Hultgren, and C. Bergsten. 2002. Prevalence and interrelationships of hoof lesions and lameness in Swedish dairy cows. Prev. Vet. Med. 54:247-263.
Manson, F. J. 1986. A study of lameness in dairy cows with reference to nutrition and hoof care. Ph.D. Thesis, The University of Glasgow, UK.

Manson, F. J., and J. D. Leaver. 1988. The influence of concentrate amount on locomotion and clinical lameness in dairy cattle. Anim. Prod. 47:185-190.

Mill, J. M., and W. R. Ward. 1994. Lameness in dairy cows and farmers' knowledge, training and awareness. Vet. Rec. 134:162-164.

National Research Council. 2001. Nutrient Requirements for Dairy Cattle. Natl. Acad. Sci. Washington, DC.

O'Callaghan, K. 2002. Lameness and associated pain in cattle-challenging traditional perceptions. In Pract. 24:214-219.

O'Callaghan, K. A. O., P. J. Cripps, D. Y. Downham, and R. D. Murray. 2003. Subjective and objective assessment of pain and discomfort due to lameness in dairy cattle. Anim. Welf. 12:605-610.

Ossent, P., P. R. Greenough, and J. J. Vermunt. 1997. Laminitis. Pages 277-292 in Lameness in Cattle. 3rd ed. P. R. Greenough, ed. W. B. Saunders, Philadelphia, PA.

Phillips, C. J. C., and I. D. Morris. 2001. The locomotion of dairy cows on floor surfaces with different frictional properties. J. Dairy Sci. 84:623-628.

Rajkondawar, P. G., A. M. Lefcourt, N. K. Neerchal, R. M. Dyer, M. A. Varner, B. Erez, and U. Tasch. 2002. The development of an objective lameness scoring system for dairy herds: Pilot study. Pages 411-414 in Proc. 12th Int. Symp. on Lameness in Ruminants, Orlando, Florida.

Russell, A. M., G. J. Rowland, S. R. Shaw, and A. D. Weaver. 1982. Survey of lameness in British dairy cattle. Vet. Rec. 111:155-160.

Somers, J. G. C. J., K. Frankena, E. N. Noordhuizen-Stassen, and J. H. M. Metz. 2003. Prevalence of claw disorders in Dutch dairy cows exposed to several floor systems. J. Dairy Sci. 86:2082-2093.

Sprecher, D. J., D. E. Hostetler, and J. B. Kaneene. 1997. A lameness scoring system that uses posture and gait to predict dairy cattle reproductive performance. Theriogenology 47:1179-1187.

Telezhenko, E., and C. Bergsten. 2005. Influence of floor type on the locomotion of dairy cows. Appl. Anim. Behav. Sci. 93:183-197.

van Eerdenburg, F. J., H. de Boer, and F. Gómez. 2003. Relationship among subclinical lameness and oestrus expression. Pages 211216 in Proc. XIth Int. Congr. Int. Soc. Anim. Hyg., Mexico City.

Warnick, L. D., D. Janssen, C. L. Guard, and Y. T. Gröhn. 2001. The effect of lameness on milk production in dairy cows. J. Dairy Sci. 84:1988-1997.

Welsh, E. M., G. Gettinby, and A. M. Nolan. 1993. Comparison of a visual analogue scale and a numerical rating scale for assessment of lameness, using sheep as a model. Am. J. Vet. Res. 54:976-983.

Whay, H. R., D. C. J. Main, L. E. Green, and A. J. F. Webster. 2003. Assessment of the welfare of dairy cattle using animal-based measurements: Direct observations and investigation of farm records. Vet. Rec. 153:197-202.

Whay, H. R., A. E. Waterman, and A. J. F. Webster. 1997. Associations between locomotion, claw lesions and nociceptive threshold in dairy heifers during the peri-partum period. Vet. J. 154:155-161.

Winckler, C., and S. Willen. 2001. The reliability and repeatability of a lameness scoring system for use as an indicator of welfare in dairy cattle. Acta Agric. Scand. A (Suppl. 30):103-107. 